\title{
Effect of superplastic deformation on the microstructure and orientation of austenite in 3207 duplex stainless steel
}

\author{
J. $\operatorname{Li}^{1}$, X. $\operatorname{Ren}^{1 *}, \mathrm{X} \cdot \mathrm{Gao}^{1,2}$ \\ ${ }^{1}$ School of Materials Science and Engineering, University of Science and Technology Beijing, \\ Beijing 100083, P. R. China \\ ${ }^{2}$ Institute for Advanced Materials and Technology, University of Science and Technology Beijing, \\ Beijing 100083, P. R. China
}

Received 8 January 2020, received in revised form 1 April 2020, accepted 3 April 2020

\begin{abstract}
Due to attractive strength, toughness, and corrosion resistance, duplex stainless steels (DSS) are widely used in various applications. The current study performs a systematic investigation on the microstructure and orientation of austenite in DSS during superplastic deformation. Results show that austenite grains became uniform, equiaxed, coarse, and some were elongated. The superplastic deformation could weaken textures in Gauss $\{011\}<100>$, Brass $\{011\}<211>$ and Copper $\{211\}<111>$ orientations. Dynamic recovery followed by continuous dynamic recrystallization occurred in austenite during superplastic deformation. Concentrated strain in softer ferrite phase leads to a slightly lower dislocation density in austenite. This paper provides new insight into the deformation mechanism of the austenite matrix during hot deformation in duplex stainless steels.
\end{abstract}

K e y w o r d s: duplex stainless steel, austenite, superplastic deformation, microstructure, orientation

\section{Introduction}

Due to their desirable combination of strength, toughness, corrosion resistance, and affordability, duplex stainless steels (DSS) are widely used in chemical processing, nuclear reactors, and other industries [13 . These properties are the result of the duplex microstructure composed of face-centered cubic (f.c.c.) austenite $(\gamma)$ and body-centered cubic (b.c.c.) ferrite $(\delta)$ [4], which also lead to superplasticity of DSS [5]. Thus hot working is one of the most important forming methods of DSS, such as forging, blow-forming, and diffusion bonding [6-8].

Previous studies show that the fraction of ferrite will be decreased while the fraction of austenite will be increased after hot working [7-11]. Thus austenite becomes the matrix during hot deformation of DSS, and it plays a decisive role in the hot deformation process. It has been proved that the austenite-based steel has higher tensile strength at room temperature because of its deformation mechanism and continuous strain hardening behavior. At the same time, it should exhibit typical planar dislocation slip characteristics during high-temperature deformation [12]. However, the microstructure evolution during superplastic deformation of austenite in the DSS has not been studied systematically.

Therefore, the current study aims to investigate the effect of superplastic deformation on microstructure and orientation of austenite. The clamping end of the superplastic sample was also observed as a comparison. This provides new insight into the deformation mechanism during hot deformation in DSS, which has both fundamental and applied significance in the light of the growing importance of DSS.

\section{Experimental}

The material used was a commercial 3207 duplex stainless steel with a composition of $0.029 \mathrm{C}, 0.15 \mathrm{Si}$, $1.03 \mathrm{Mn}, 0.014 \mathrm{P}, 31.05 \mathrm{Cr}, 3.88 \mathrm{Mo}, 6.64 \mathrm{Ni}, 0.53 \mathrm{~N}$

\footnotetext{
*Corresponding author: tel.: +8610 82376475; e-mail address: rxp33@ustb.edu.cn
} 

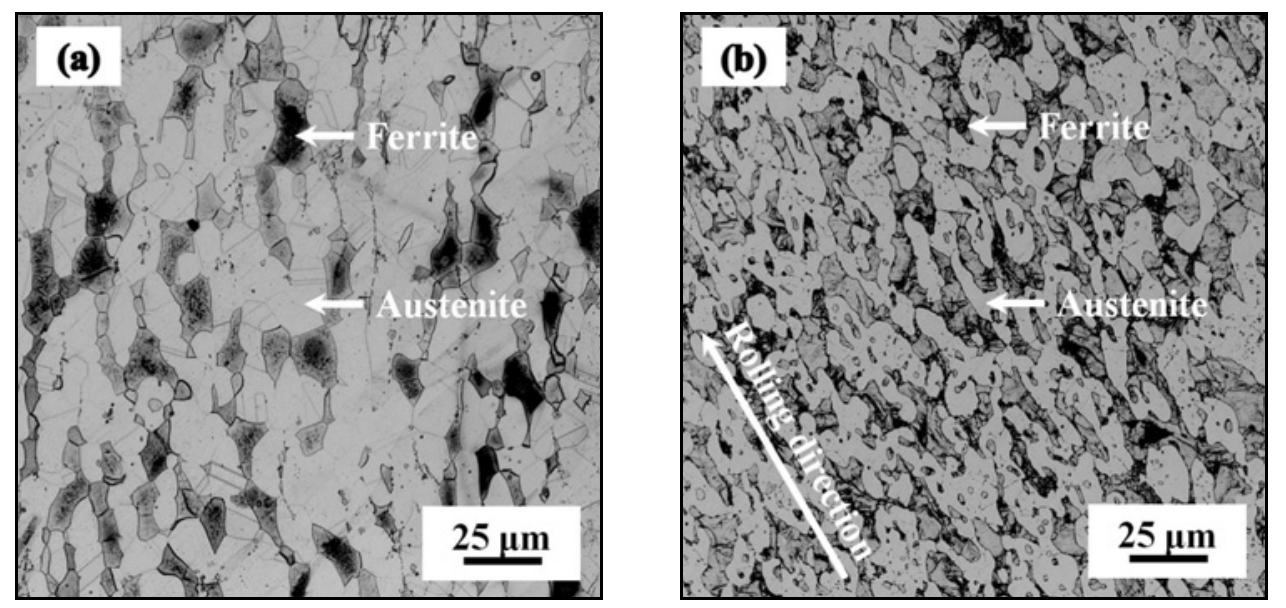

Fig. 1. The microstructure of the solution-treated (a) and cold-rolled (b) 3207 duplex stainless steels.

(in wt.\%) and remainder Fe. The initial material was received as a hot-rolled slab with a $4 \mathrm{~mm}$ thickness. The hot-rolled steel was then solution treated at $1250{ }^{\circ} \mathrm{C}$ and held isothermally for $30 \mathrm{~min}$ in an SRJX-8-13A box type heater with the temperature control accuracy of $\pm 5{ }^{\circ} \mathrm{C}$, followed by water quenching. Then the slab was rolled to $2 \mathrm{~mm}$ with an $80 \%$ reduction in room temperature. Metallographic specimens of solution-treated and cold-rolled samples were ground and polished according to standard procedures and etched by aqua regia. The microstructure of the samples was characterized using an Imager.M2m optical microscope (OM).

Tensile specimens with a thickness of $2 \mathrm{~mm}$, a gauge length of $10 \mathrm{~mm}$, and a width of $6 \mathrm{~mm}$ were machined directly from the cold-rolled sample along the rolling direction. The superplastic deformation was realized by a hot tensile test, which was carried out on an SK10-70300 constant temperature tensile testing machine with a temperature control accuracy of $\pm 4{ }^{\circ} \mathrm{C}$. The sample was held for $1 \mathrm{~min}$ at $950{ }^{\circ} \mathrm{C}$ before the superplastic tensile test to ensure a uniform temperature distribution. The initial strain rate was $1.5 \times 10^{-3} \mathrm{~s}^{-1}$. Both the crosshead speed and temperature were kept constant during the test; then, the sample was quenched in water immediately.

The electron backscatter diffraction (EBSD) technique was employed to characterize the microstructure and texture evolution of the sample after the superplastic tensile test. EBSD samples were taken on both gauge (marked as sample "after hot tensile testing") and grip (marked as sample "after heat treatment") of the 3207 duplex stainless steel after tensile testing. They were electro-polished for 3-8 min with a solution of chromium anhydride $120 \mathrm{~g}+$ orthophosphoric acid $\left(\mathrm{H}_{3} \mathrm{PO}_{4}\right) 280 \mathrm{~mL}+$ sulphuric acid $\left(\mathrm{H}_{2} \mathrm{SO}_{4}\right) 220 \mathrm{~mL}+$ deionized water $\left(\mathrm{H}_{2} \mathrm{O}\right) 40 \mathrm{~mL}$, at a voltage of $6-8 \mathrm{~V}$ and a constant temperature of $80-95^{\circ} \mathrm{C}$. The EBSD analyses were carried out with a JEOL JSM-7800F field emission scanning electron microscope (SEM) op- erating at an acceleration voltage of $20 \mathrm{kV}$. Oxford Instruments Nordlys Nano EBSD system equipped with Channel 5 software was used for analysis. Fractions of recrystallized, substructured, and deformed grains were distinguished by the EBSD system automatically depending on the density of subgrain boundaries. The subgrain boundary is defined as the boundary with misorientation less than $2^{\circ}$. The orientation distributing function (ODF) maps were produced by the EBSD system to describe the orientation details. The orientation lines were drawn according to the ODF maps to quantitatively analyze the aggregation process of the austenite grain orientation.

\section{Results and discussion}

\subsection{Characterization of experimental material}

The microstructures of the 3207 duplex stainless steels before the superplastic tensile test are shown in Fig. 1. In the optical micrographs, austenite and ferrite were distinguished by the contrast of gray and dark, respectively [13]. The solution-treated microstructure consists of austenite and ferrite, and the equiaxed ferrite is located in the austenite matrix with equiaxed grains, as shown in Fig. 1a. The volume fractions of austenite and ferrite are about 58 and $42 \%$, respectively, measured by Imagetool software (average value of five images). After cold rolling, both austenite and ferrite are elongated along the rolling direction, and the microstructure is uniform, as shown in Fig. 1b. The volume fractions of austenite and ferrite are about 59 and $41 \%$, respectively, measured by Imagetool software (average value of five images). The average grain size of austenite is about $6 \mu \mathrm{m}$ in the normal direction (vertical to the rolling direction in Fig. 1b) of the cold-rolled 3207 duplex stainless steel measured by Imagetool software. 

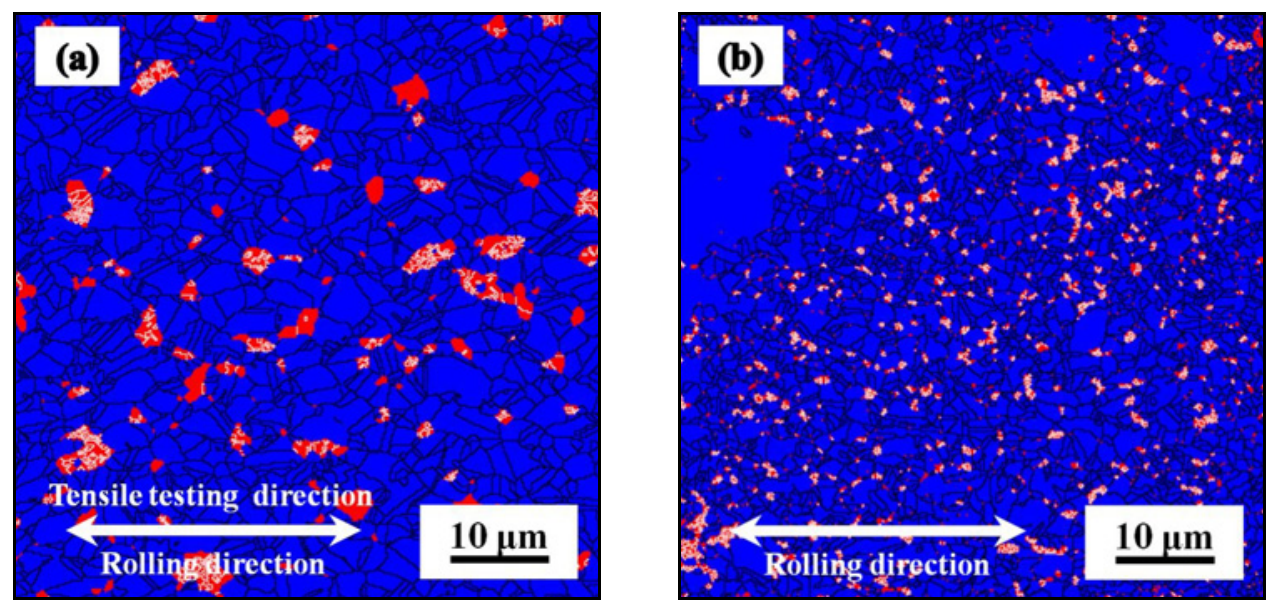

Fig. 2. Phase maps of samples after hot tensile testing (a) and heat treatment (b). The ferrite represented as "red" with "white" grain boundaries, while the austenite represented as "blue" with "black" grain boundaries.
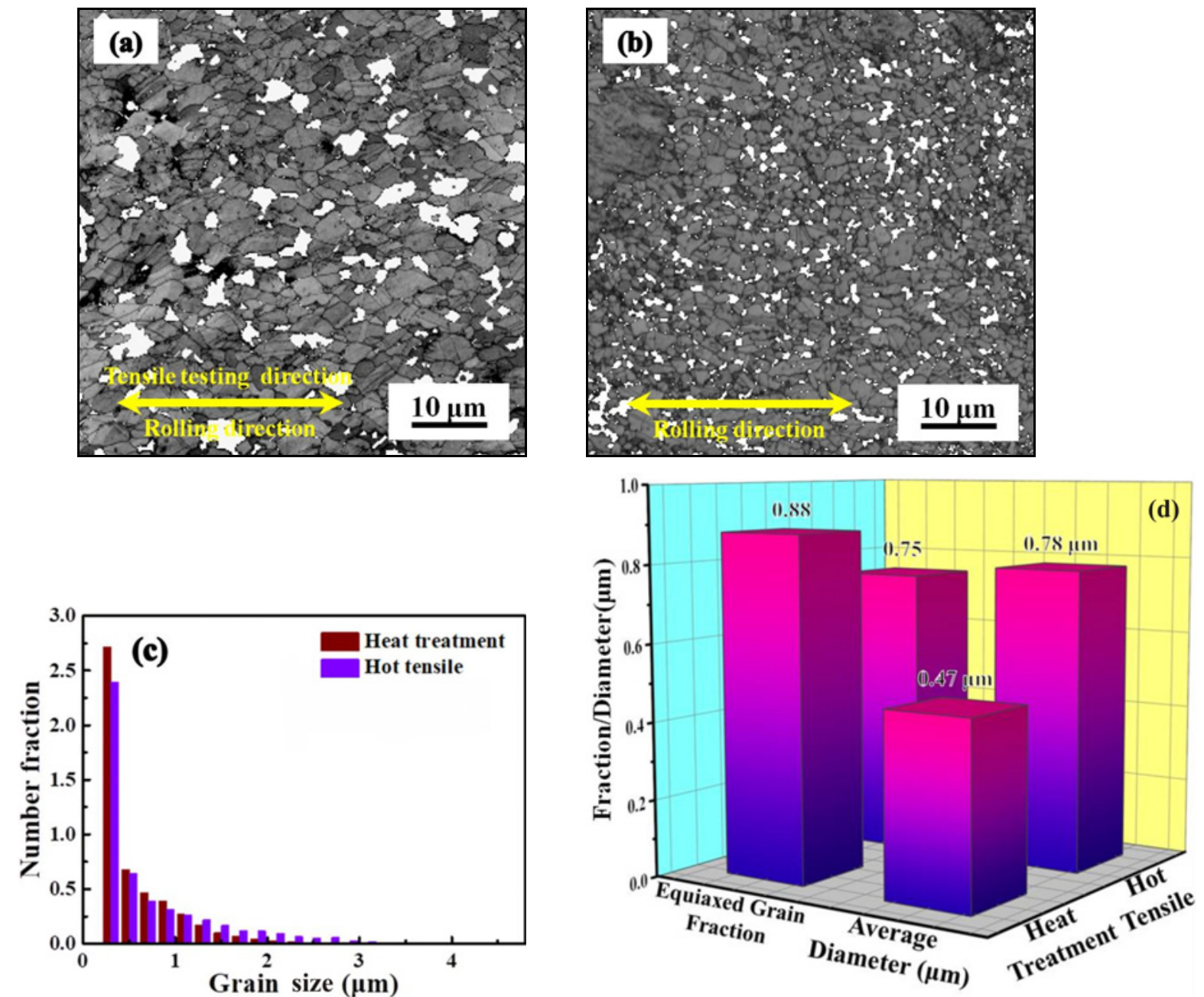

Fig. 3. Grain morphology and size of austenite: (a) grain morphology after hot tensile testing; (b) grain morphology after heat treatment; (c) related grain size distribution and (d) average grain size and a fraction of equiaxed grains.

\subsection{Microstructure evolution}

The phase maps of the samples after hot tensile testing and heat treatment, respectively, are shown in Fig. 2. It is clear that the equiaxed ferrite is located in the austenite matrix. Fractions of ferrite are 10 and 


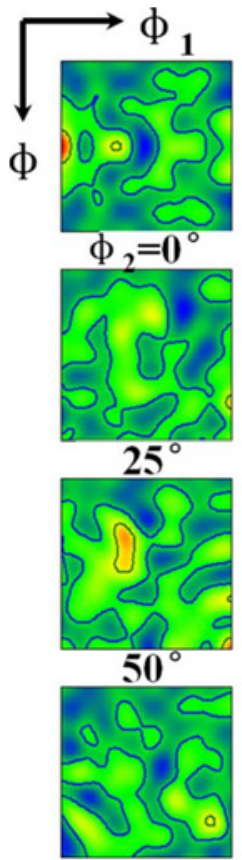

$75^{\circ}$
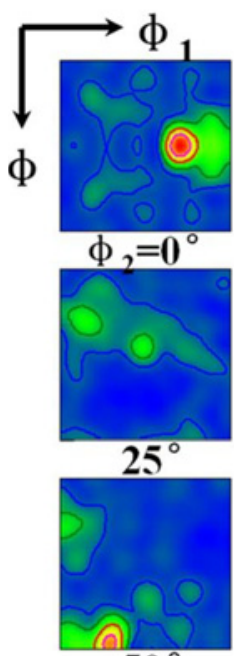

$50^{\circ}$

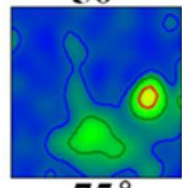

$75^{\circ}$

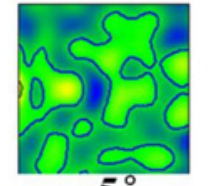

5

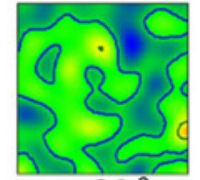

$30^{\circ}$

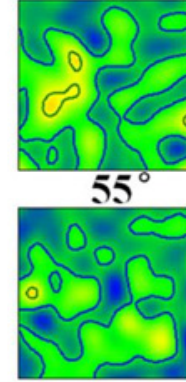

$80^{\circ}$

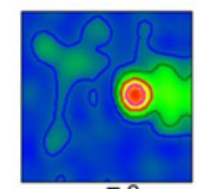

$5^{\circ}$

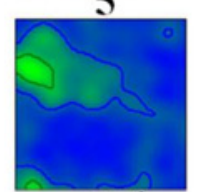

$30^{\circ}$

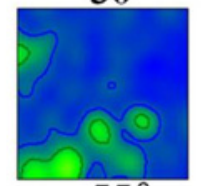

$55^{\circ}$

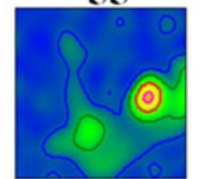

$80^{\circ}$

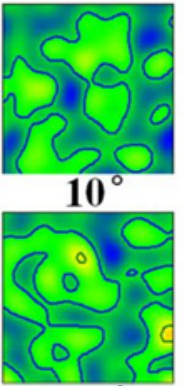

$35^{\circ}$

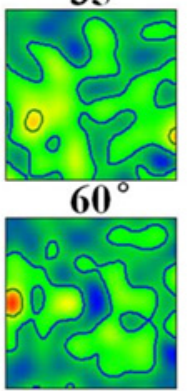

$85^{\circ}$
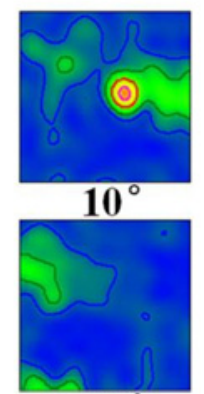

$35^{\circ}$

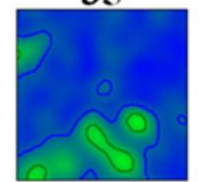

$60^{\circ}$

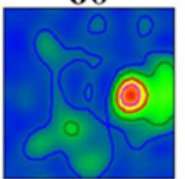

$85^{\circ}$

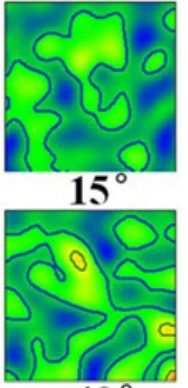

$40^{\circ}$

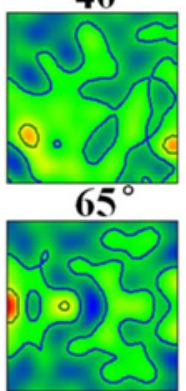

$90^{\circ}$

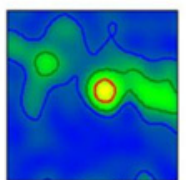

$15^{\circ}$

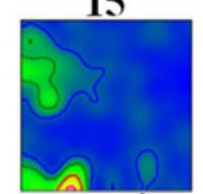

$40^{\circ}$

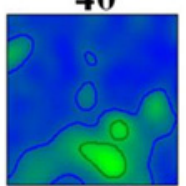

$65^{\circ}$

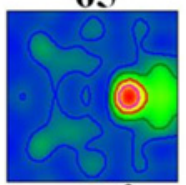

$90^{\circ}$

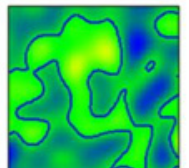

$20^{\circ}$

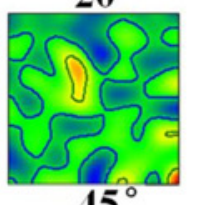

$45^{\circ}$

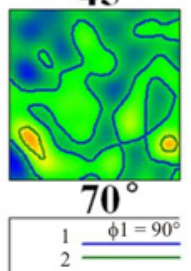

(a)

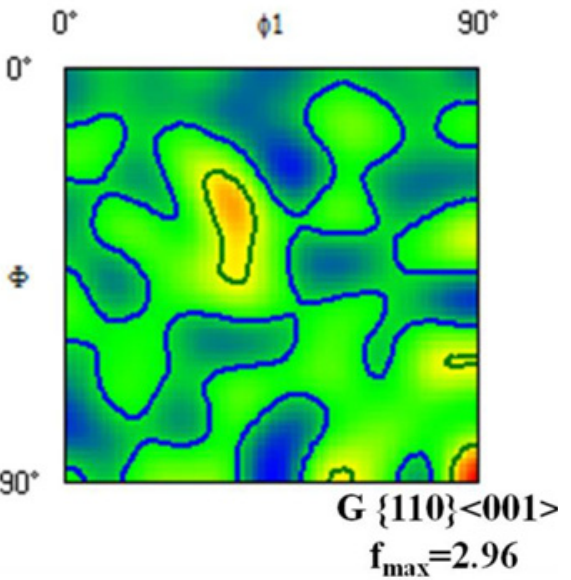

Fig. 4. Experimental complete ODF maps and $\phi_{2}=45^{\circ}$ sections of austenite in 3207 duplex stainless steels after hot tensile testing (a) and heat treatment (b).

$9 \%$ measured by the EBSD technique in samples after hot tensile testing and heat treatment, respectively. However, ferrite is coarser and more concentrated in the sample after hot tensile testing, compared to the sample after heat treatment. Anyway, austenite has become the major phase in the 3207 duplex stainless steel after hot tensile testing or heat treatment, which should be further investigated.

Grain morphology and size distribution of austen- ite are shown in Fig. 3. The austenite after hot tensile testing is distributed uniformly with equiaxed grains (defined as shape aspect ratio $<2$, Fig. 3a), while the austenite after heat treatment is composed of finer equiaxed grains generally (Fig. 3b). However, abnormal grain growth can be observed in the austenite after heat treatment, resulting in some grains larger than $10 \mu \mathrm{m}$, as shown in Fig. 3b.

The austenite grain size distributions are shown in 
Fig. 3c. According to the characterization of distributions, grains were defined as fine grains $(\mathrm{FG})<1 \mu \mathrm{m}$, small grains (SG) for $1-3 \mu \mathrm{m}$, and coarse grains $(\mathrm{CG})$ $>3 \mu \mathrm{m}$, respectively. As shown in Fig. 3c, the proportion of FG decreased to $75 \%$ after hot tensile testing compared with $85 \%$ after heat treatment measured by the EBSD technique. Correspondingly, there is an obvious increase of CG from nearly $0 \%$ after heat treatment to more than $1 \%$ after hot tensile testing measured by the EBSD technique. It can be concluded from the above analysis that the hot tensile process is beneficial in grain coarsening for the 3207 duplex stainless steel. This process can effectively improve the softening effect, which could prevent localized necking and contribute to a longer elongation [14].

A quantitative description of the average austenite grain sizes and the grain shape are shown in Fig. 3d. The fraction of equiaxed austenite grains decreased from 0.88 (after heat treatment) to 0.75 (after hot tensile testing), indicating some grains were elongated during the hot tensile process. The average austenite grain size increased from 0.47 to $0.78 \mu \mathrm{m}$. However, the grain size is fine enough for grain boundary sliding during superplastic deformation [15].

\subsection{Texture changes}

A complete way of representing texture requires an orientation distribution function (ODF) analysis. In an ODF analysis, all the possible orientations are projected in a 3D Euler space defined by three Euler's angles of $\phi, \phi_{1}$, and $\phi_{2}$, following the Bunge notation [16]. Serial $2 \mathrm{D}$ sections of the $3 \mathrm{D}$ cube containing values of $\phi, \phi_{1}$, and $\phi_{2}$ from $0^{\circ}$ to $90^{\circ}$ as well as the $\phi_{2}=$ $45^{\circ}$ section, which include the most important texture components found in f.c.c. metals [17], are shown in Fig. 4. It can be seen clearly that the main texture of austenite after hot tensile testing is weak Gauss $\{011\}<100>(\mathrm{G})$ texture, and its orientation density value is only 2.96 , as shown in Fig. 4a. While moderate $\{110\}<3-22>$ texture can be observed in austenite after heat treatment (calculated by the Textool software), with an orientation density value of 8.11 (Fig. 4b). The peak ODF value for austenite after hot tensile treatment is too small; thus, the orientation distribution could be regarded as random [18]. It can be concluded that the hot tensile process could weaken the texture intensity, resulting in weak deformation texture in austenite. This result is also demonstrated in previous studies for these materials $[14,19]$.

Related research demonstrates that the deformation textures of f.c.c. metals mainly aggregate along $\alpha$ - and $\beta$-fiber orientation lines $[17,20]$. Thus we can quantitatively analyze the aggregation process of the austenite grain orientation by $\alpha$ - and $\beta$-fiber orientation lines. Figure 5 shows the orientation lines analysis of austenite textures after hot tensile testing and heat
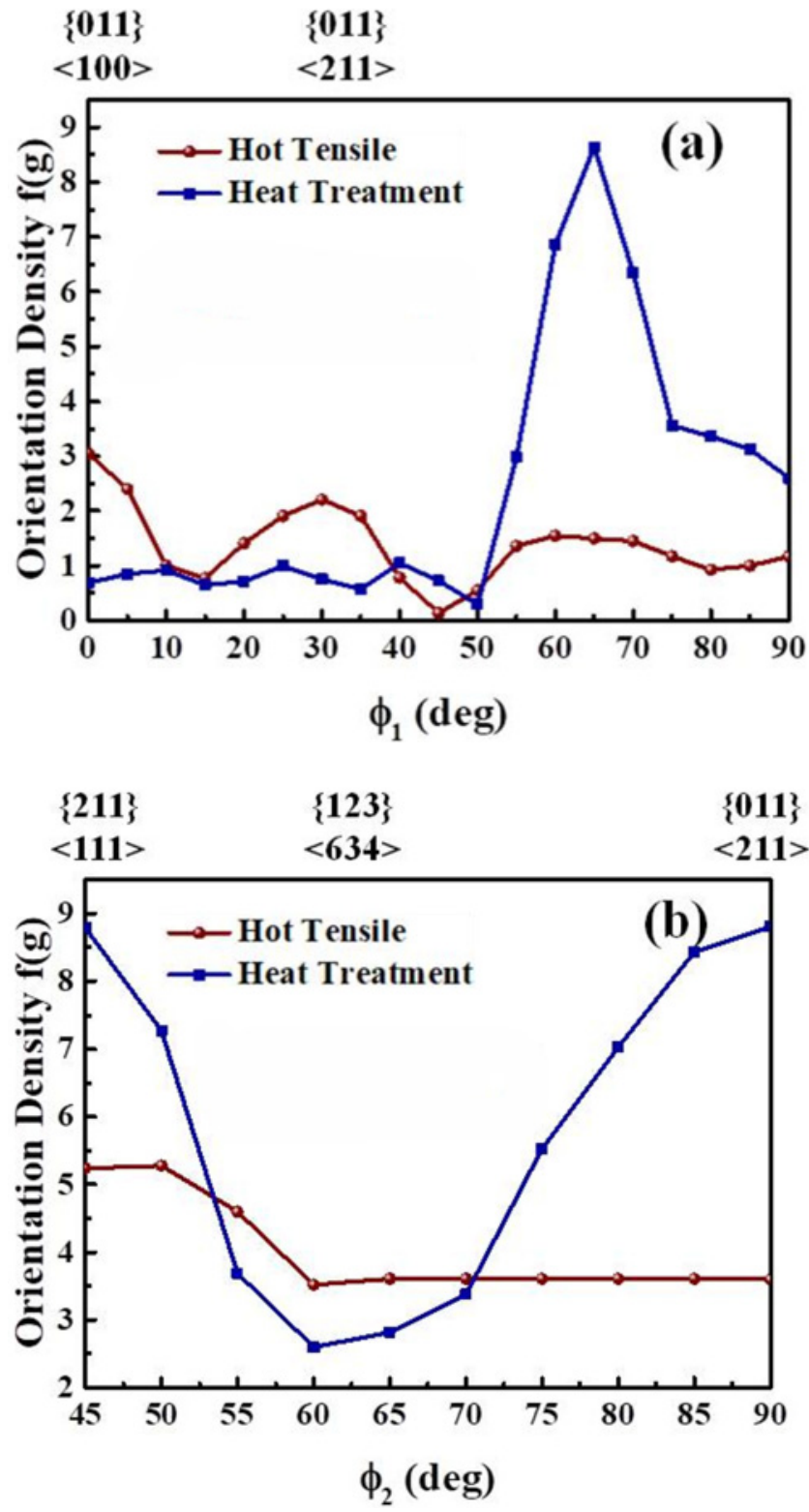

Fig. 5. Orientation lines analysis of austenite textures: (a) $\alpha$-fiber, (b) $\beta$-fiber position.

treatment, respectively. It is clear that the austenite grain after heat treatment shows a strong peak of orientation density in $\phi_{1}=65^{\circ}$, which does not belong to deformation textures; while the austenite grains after hot tensile testing show weak textures in Gauss $\{011\}<100>(\mathrm{G})$ and Brass $\{011\}<211>$ (B) orientation, as shown in Fig. 5a. It can also be found that the austenite grains after heat treatment are slightly concentrated in the Copper $\{211\}<111>$ (C) and Brass $\{011\}<211>$ (B) orientation, while the austenite grain after hot tensile process concentrated in Copper $\{211\}<111>(\mathrm{C})$ orientation with a slightly lower degree, as shown in Fig. 5b. Figure 5c shows $\beta$-fiber position lines in the Euler angle space, which 
(a)

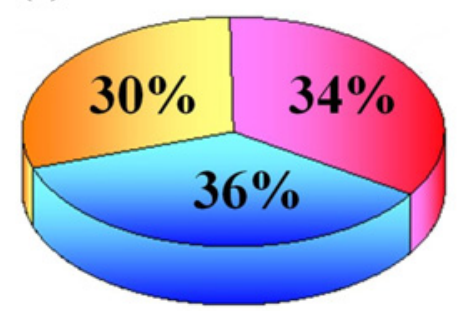

(b)

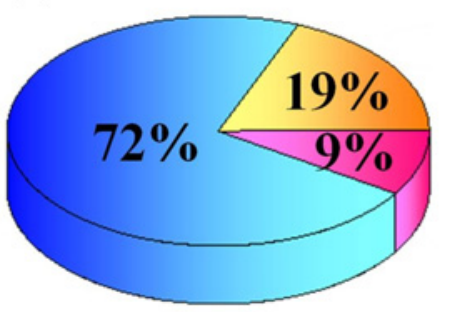

Recrystallized Substructured Deform ed

Fig. 6. Fractions of recrystallized, substructured, and deformed austenite grains of 3207 duplex stainless steel after hot tensile testing (a) and heat treatment (b), respectively.

is smoothly changed. In summary, the superplastic deformation process affects weakened textures of the austenite grains in 3207 duplex stainless steel.

\subsection{Recrystallization behavior}

Fractions of recrystallized, substructured, and deformed austenite grains of 3207 duplex stainless steel after hot tensile testing and heat treatment are shown in Fig. 6, respectively. It can be observed that the fraction of recrystallized austenite grains after hot tensile testing is lower than that after heat treatment, while the fractions of substructured and deformed austenite grains are higher than those after heat treatment. It should be noted that the deformed and substructured austenite grains shown in Fig. 6b are remaining from the cold rolling process, without further deformation. Thus most of the deformed and substructured austenite grains in Fig. 6a are introduced by the hot tensile process.

Previous studies found that the f.c.c. austenite in DSS undergoes dynamic recrystallization (DRX) with a limited dynamic recovery (DRV) during hot deformation because of its high stack fault energy [21, 22], and work hardening is the dominant mechanism until DRX occurred [23]. Thus the substructured and deformed austenite grains should be the effect of DRX.

To investigate the DRX mechanism of austenite during hot tensile testing, the misorientation angle distributions are shown in Fig. 7. The correlated misorientation means the misorientation between every two grains; the uncorrelated misorientation means the misorientation between grain and the initial identified grain; the random misorientation angle distribution represents standard misorientation angle distribution when no texture exists in the structure. The fractions of low angle grain boundaries (LAGBs, $2^{\circ}-$ $10^{\circ}$ ) and high angle grain boundaries (HAGBs, $>10^{\circ}$ ) are 15 and $85 \%$ for austenite after hot tensile testing while 6 and $94 \%$ for austenite after heat treatment, respectively. The fraction of LAGBs of austenite after hot tensile testing is slightly higher than that of austenite after heat treatment. The LAGBs are formed in the initial stage of superplastic deformation,
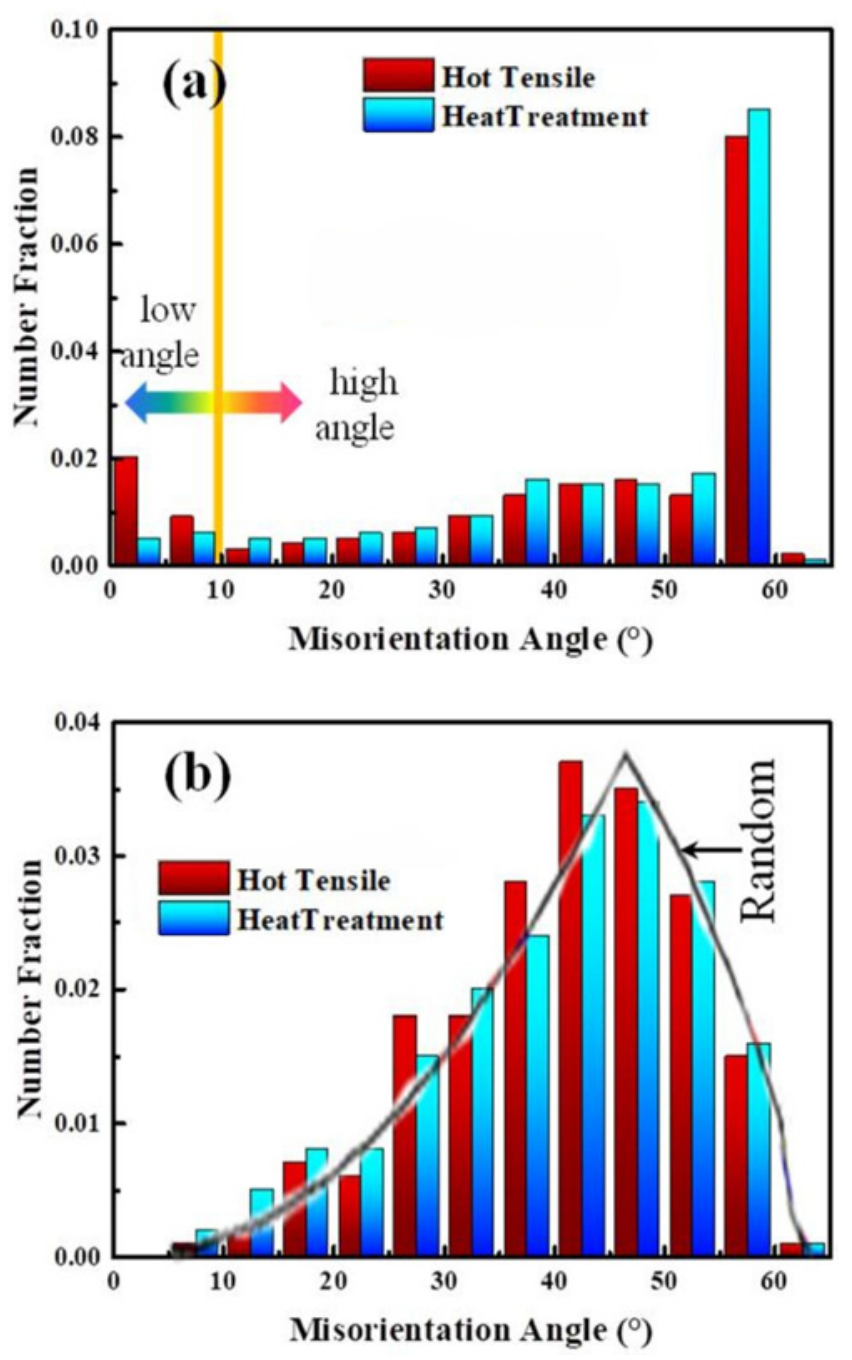

Fig. 7. Misorientation angle distributions of austenite after hot tensile testing and heat treatment, respectively: (a) correlated misorientation angle distributions and (b) uncorrelated and random misorientation angle distributions.

in which only dynamic recovery (DRV), but little subgrain growth or recrystallization, occurred [15]. It is well known that continuous dynamic recrystallization (CDRX) and discontinuous dynamic recrystallization 
(DDRX) are fundamental mechanisms for DRX [14]. A significant characteristic of CDRX is the progressive subgrain rotation occurring at short-range interaction, which leads to a continuous increase in the misorientation for LAGBs [24]. Thus LAGBs can potentially evolve into HAGBs, by which the deformed or recovered microstructures transform into recrystallized microstructures [25]. In contrast, DDRX involves the nucleation and growth process of new grains. The main feature of DDRX nucleation is the local bulging of serrated grain boundaries, which can hardly be observed in the austenite after hot tensile testing, as shown in Figs. 2a and 3a. Based on the discussion mentioned above, it can be clearly found that the primary recrystallization mechanism during hot tensile testing is CDRX.

Moreover, austenite grains after both hot tensile testing and heat treatment have a high similarity between uncorrected and random curves, as shown in Fig. 7b. It suggests that the recrystallized microstructures possess a random texture, and the prominent rolling deformation textures have almost disappeared $[14]$.

\section{Conclusions}

In conclusion, the effect of superplastic deformation on microstructure and orientation of austenite in 3207 duplex stainless steel has been studied by using the EBSD technique and TEM. Based on the analysis of experimental results, the main outcomes of this work could be summarized as follows:

(1) After superplastic deformation, the fraction of austenite was increased. The elongated grains after cold rolling have changed, showing equiaxed ferrite located in the austenite matrix. Ferrite is coarser and more concentrated in the sample after hot tensile testing than the sample after heat treatment.

(2) After superplastic deformation, austenite grains are uniformly distributed and equiaxed, and they are coarser than austenite grains after heat treatment. Some austenite grains were elongated during the hot tensile process.

(3) Copper $\{211\}<111>$ (C), Brass $\{011\}<211>$ (B) and $\{110\}<3-22>$ textures formed in austenite after heat treatment while the austenite after hot tensile testing shows weak textures in Gauss $\{011\}<100>$ (G), Brass $\{011\}<211>$ (B) and Copper $\{211\}<111>$ (C) orientation with a slightly lower degree. The superplastic deformation process affects weakened textures of the austenite in 3207 duplex stainless steel.

(4) In the initial stage of superplastic deformation, only dynamic recovery occurred in austenite. Then CDRX occurred in austenite, resulting in the deformed or recovered microstructures transforming into recrystallized microstructures.

\section{References}

[1] T. L. Roland, Study of the corrosion behaviour of S32101 duplex and 410 martensitic stainless steel for application in oil refinery distillation systems, J. Mater. Res. Tech. 6 (2017) 203-212. doi:10.1016/j.jmrt.2016.11.001

[2] J. D. Tucker, M. K. Miller, G. A. Young, Assessment of thermal embrittlement in duplex stainless steels 2003 and 2205 for nuclear power applications, Acta Mater. 87 (2015) 15-24. doi:10.1016/j.actamat.2014.12.012

[3] H. Qu, H. Hou, P. Li, X. Ren, The effect of thermal cycling in superplastic diffusion bonding of heterogeneous duplex stainless steel, Mater. Design 96 (2016) 499-505. doi:10.1016/j.matdes.2016.01.147

[4] S. Mburu, R. P. Kolli, D. E. Perea, S. C. Schwarm, A. Eaton, J. Liu, S. Patel, Effect of aging temperature on phase decomposition and mechanical properties in cast duplex stainless steels, Mater. Sci. Eng. A 690 (2017) 365-377. doi:10.1016/j.msea.2017.03.011

[5] M. Sagradi, D. Pulino-Sagradi, R. E. Medrano, The effect of the microstructure on the superplasticity of a duplex stainless steel, Acta Mater. 46 (1998) 38573862. doi:10.1016/S1359-6454(98)00087-1

[6] M. Ferrante, M. De Mello, A. Lesko, SAF 2205 duplex stainless steel HAZ microstructural changes during long term ageing at $380^{\circ} \mathrm{C}$, Kovove Mater. 37 (1999) $120-128$.

[7] E. V. Morales, J. A. Pozo, L. Olaya, E. Kassab, J. A. C. Ponciano, K. Ghavami, I. S. Bott, Remarks on the evolution and performance of the different austenite morphologies at the simulated HAZs of a $2205 \mathrm{du}-$ plex stainless steel, J. Mater. Res. Tech. 8 (2019) 39363949. doi:10.1016/j.jmrt.2019.07.002

[8] S. Li, X. Ren, H. Hou, The effect of thermal cycling in superplastic diffusion bonding of $2205 \mathrm{du}-$ plex stainless steel, Mater. Design 86 (2015) 582-586. doi:10.1016/j.matdes.2015.07.094

[9] T. S. Byun, Y. Yang, N. R. Overman, J. T. Busby, Thermal aging phenomena in cast duplex stainless steels, JOM 68 (2016) 507-516. doi:10.1007/s11837-015-1709-9

[10] N. Haghdadi, D. Abou-Ras, P. Cizek, P. D. Hodgson, A. D. Rollett, H. Beladi, Austenite-ferrite interface crystallography dependence of sigma phase precipitation using the five-parameter characterization approach, Mater. Lett. 196 (2017) 264-268. doi:10.1016/j.matlet.2017.03.090

[11] D. C. Dos Santos, R. Magnabosco, Intermetallic phases formation during short aging between $850^{\circ} \mathrm{C}$ and $950^{\circ} \mathrm{C}$ of a superduplex stainless steel, J. Mater. Res. Tech. 1 (2012) 71-74. doi:10.1016/S2238-7854(12)70013-3

[12] Y. P. Li, R. B. Song, E. D. Wen, F. Q. Yang, Hot Deformation and dynamic recrystallization behavior of austenite-based low-density Fe-Mn-Al-C steel, Acta Metall. Sin. Engl. 29 (2016) 441-449. doi:10.1007/s40195-016-0406-1

[13] S. Li, X. Ren, X. Ji, Y. Gui, Effects of microstructure changes on the superplasticity of 2205 duplex stainless steel, Mater. Design 55 (2014) 146-151. doi:10.1016/j.matdes.2013.09.042

[14] Z. Liu, P. Li, L. Xiong, T. Liu, L. He, Hightemperature tensile deformation behavior and mi- 
crostructure evolution of Ti55 titanium alloy, Mater. Sci. Eng. A 680 (2017) 259-269. doi:10.1016/j.msea.2016.10.095

[15] L. Jia, X. Ren, H. Hou, Y. Zhang, Microstructural evolution and superplastic deformation mechanisms of asrolled 2A97 alloy at low temperature, Mater. Sci. Eng. A 759 (2019) 19-29. doi:10.1016/i.msea.2019.04.102

[16] S. Pal, M. E. Alam, S. A. Maloy, D. T. Hoelzer, G. R. Odette, Texture evolution and microcracking mechanisms in as-extruded and cross-rolled conditions of a 14YWT nanostructured ferritic alloy, Acta Mater. 152 (2018) 338-357. doi:10.1016/j.actamat.2018.03.045

[17] X. Wang, X. Liu, J. Xie, Mechanism of surface texture evolution in pure copper strips subjected to double rolling, Prog. Nat. Sci. Mater. 24 (2014) 75-82. doi:10.1016/i.pnsc.2014.01.014

[18] J. Y. Kang, H. Kim, K. I. Kim, C. H. Lee, H. N. Han, K. H. Oh, T. H. Lee, Effect of austenitic texture on tensile behavior of lean duplex stainless steel with transformation induced plasticity (TRIP), Mater. Sci. Eng. A 681 (2017) 114-120. doi:10.1016/j.msea.2016.11.001

[19] L. H. Wu, C. L. Jia, S. C. Han, N. Li, D. R. Ni, B. L. Xiao, Z. Y. Ma, M. J. Fu, Y. Q. Wang, Y. S. Zeng, Superplastic deformation behavior of lamellar microstructure in a hydrogenated friction stir welded Ti-6Al-4V joint, J. Alloy Compd. 787 (2019) 13201326. doi:10.1016/i.jallcom.2019.02.182

[20] M. Song, X. Liu, L. Liu, Size effect on mechanical properties and texture of pure copper foil by cold rolling, Materials 10 (2017) 538.

doi: $10.3390 / \mathrm{ma10050538}$
[21] O. Balancin, W. A. M. Hoffmann, J. J. Jonas, Influence of microstructure on the flow behavior of duplex stainless steels at high temperatures, Metall. Mater. Trans. A 31 (2000) 1353-1364. doi:10.1007/s11661-000-0254-4

[22] L. Duprez, B. C. De Cooman, N. Akdut, Flow stress and ductility of duplex stainless steel during high-temperature torsion deformation, Metall. Mater. Trans. A 33 (2002) 1931-1938. doi:10.1007/s11661-002-0026-4

[23] H. L. Wei, G. Q. Liu, X. Xiao, M. H. Zhang, Dynamic recrystallization behavior of a medium carbon vanadium microalloyed steel, Mater. Sci. Eng. A 573 (2013) 215-221. doi:10.1016/i.msea.2013.03.009

[24] D. A. H. R. D. Doherty, E. J. Humphreys, J. J. Jonas, D. Juul Jensen, M. E. Kassner, W. E. King, T. R. McNelley, H. J. McQueen, A. D. Rollett, Current issues in recrystallization: A review, Mater. Sci. Eng. A 238 (1997) 219-274. doi:10.1016/S0921-5093(97)00424-3

[25] M. R. Barnett, F. Montheillet, The generation of new high-angle boundaries in aluminium during hot torsion, Acta Mater. 50 (2002) 2285-2296. doi:10.1016/S1359-6454(02)00048-4

[26] L. Zhang, R. Song, Z. Chao, F. Yang, Work hardening behavior involving the substructural evolution of an austenite-ferrite Fe-Mn-Al-C steel, Mater. Sci. Eng. A 640 (2015) 225-234. doi:10.1016/j.msea.2015.05.108

[27] Y. Han, D. N. Zou, Z. Y. Chen, G. W. Fan, W. Zhang, Investigation on hot deformation behavior of $00 \mathrm{Cr} 23 \mathrm{Ni} 4 \mathrm{~N}$ duplex stainless steel under medium-high strain rates, Mater. Charact. 62 (2011) 198-203. doi:10.1016/j.matchar.2010.11.013 